\title{
HAWANA
}

Is There Such a Thing as Chinese Philosophy? Arguments of an Implicit Debate Author(s): Carine Defoort

Source: Philosophy East and West, Vol. 51, No. 3, Eighth East-West Philosophers' Conference (Jul., 2001), pp. 393-413

Published by: University of Hawai'i Press

Stable URL: http://www.jstor.org/stable/1399849

Accessed: 09/03/2010 02:24

Your use of the JSTOR archive indicates your acceptance of JSTOR's Terms and Conditions of Use, available at http://www.jstor.org/page/info/about/policies/terms.jsp. JSTOR's Terms and Conditions of Use provides, in part, that unless you have obtained prior permission, you may not download an entire issue of a journal or multiple copies of articles, and you may use content in the JSTOR archive only for your personal, non-commercial use.

Please contact the publisher regarding any further use of this work. Publisher contact information may be obtained at http://www.jstor.org/action/showPublisher?publisherCode=uhp.

Each copy of any part of a JSTOR transmission must contain the same copyright notice that appears on the screen or printed page of such transmission.

JSTOR is a not-for-profit service that helps scholars, researchers, and students discover, use, and build upon a wide range of content in a trusted digital archive. We use information technology and tools to increase productivity and facilitate new forms of scholarship. For more information about JSTOR, please contact support@ jstor.org.

University of Hawai'i Press is collaborating with JSTOR to digitize, preserve and extend access to Philosophy East and West. 


\title{
COMMENT AND DISCUSSION
}

\author{
Is There Such a Thing as Chinese Philosophy? Arguments of an \\ Implicit Debate
}

\section{Carine Defoort}

Department Oosterse en Slavische Studies, Katholieke Universiteit Leuven

"Philosophy" is the showpiece of our university: every freshman student is required to follow a general course on philosophy. But regardless of the ways in which this course may be considered general, the fact is that attention to non-Western cultures is absent throughout. The course is not titled "General Western Philosophy," and yet philosophy is, quite simply, a Western matter. This demands no further explanation; it is taken for granted. It should come as no surprise that China starts from an entirely different presupposition. Several philosophy departments have a branch dealing with Chinese philosophy, analogous to those offering Western and often even Indian philosophy. But not one Chinese university teaches exclusively Chinese philosophy, let alone under the title "General Philosophy." 1

In the light of such an imposing state of affairs, the question inevitably comes to the fore: is there indeed such a thing as "Chinese philosophy"? However, the degree of certainty with which the conflicting positions are held is not the result of thorough research, painstaking debate, or well-founded reasoning. For these have hardly even begun. In both the West and China, the answer to this question consists mostly of implicit presuppositions. It belongs less to the domain of explicit opinion than to the implicit frame within which we function: the organization of universities, bookshops, journals, and conferences all confirm a vision that, in fact, they have seldom explicitly discussed. The topic is therefore rather sensitive: any explicit rejection of the existence of Chinese philosophy implies not only a painful break with the raison $d^{\prime}$ être of more than a thousand Chinese academics but also a blow to China's national pride. On the other hand, the insistence that general introductory courses to philosophy ought to include philosophical traditions laid claim to by other cultures would certainly disturb Western colleagues in the field.

From this one might be inclined to conclude that such strong emotions and exaggerated sensitivities - a Western chauvinism on the one hand and an overly sensitive Chinese self-insistence on the other-are obstacles to a mature discussion of this nevertheless fundamental question. The arguments presented here, on the contrary, shall endeavor to show that this conclusion is not entirely correct. Several concrete arguments have been forwarded in this debate, and insofar as this conclusion is correct, I will argue that this very sensitivity is an interesting phenomenon, one that is unjustly being neglected.

The following analysis of the implicit debate has a relevance beyond the field of "Chinese philosophy" since a similar problematic forwards itself not only in 
analogous controversies around entities such as "Chinese science" or "Chinese religion" 2 but also in the case of other non-Western cultures reinterpreting their tradition in terms of modern Western concepts. The existence of Chinese philosophy thus acts as a case study for a wider problematic.

It is certainly not my intention to solve the crucial question concerning the legitimacy of Chinese philosophy once and for all-this would be an impossible task given the indecision governing the definition of the concept of philosophy even in the West. Nor do I wish to call into question the legitimacy or value of two domains that are closely adjacent to the theme of this essay, namely "philosophy in China" the philosophical activities of contemporary Chinese academics-and current "Chinese philosophy," insofar as this refers to a purely geographical variant of something like contemporary "Continental philosophy." 3 The arguments presented here concern only the traditional Chinese body of thought, which is generally labeled as "Chinese philosophy." A clear definition of our domain is thus our first task.

\section{The Expression "Chinese Philosophy"}

Doubt over the legitimacy of Chinese philosophy is not exclusively the result of Western chauvinism. Indeed, the expression "Chinese philosophy" encompasses a strange paradox, which threatens to call its very identity into question. Just like other concepts such as "science" or "human rights," philosophy, by definition, makes a certain claim to universality, without thereby denying its particular, Western origin. "Spanish science" or "Swiss human rights" sounds strange to our ears because the adjectives in these expressions pose a threat to the universal pretensions of the respective nouns. Whatever these expressions might mean, we are not inclined to accept that they refer to a type of science or human rights that is only valid in these countries. Philosophy is somewhat more lenient in this respect: we are accustomed to such expressions as "Continental" or "Anglo-Saxon" philosophy, denoting different types or genres within the philosophical tradition. But even here we do not accept that the adjective stakes such a claim upon the noun that "Continental philosophy" could only be grasped by the European continental mind. In the expression "Chinese philosophy," however, the grip of the adjective upon the noun appears so strong that philosophy risks being suffocated.

One important reason for this is that the term "philosophy" — just like many other Western terms - has been applied to the Chinese tradition in retrospect. During the nineteenth century, Japan opened its doors and turned to the West for inspiration and modernization. So did China with the coming of the twentieth century, sending students to Japan to learn of its success. A Japanese scholar, Nishi Amane (1829-1887), had studied in the Netherlands and translated books into Japanese, among which were some on philosophy (in 1873). He invented a Japanese term on the basis of two Chinese characters: the "study" of "wisdom" 哲學—tetsugaku in Japanese, zhexue in Chinese. ${ }^{4}$ This was not particularly new; already in the seventeenth century, Western missionaries had labeled the great Chinese masters 
and other classics (among them the Yijing or Book of Changes) as philosophy, and this while their Chinese contemporaries described Aristotle's work in Chinese terms (qiongli gewu 窮理格物). ${ }^{5}$ What was new at the end of the nineteenth century was the disappearance of this cultural balance labeling the other in one's own terms. Not only did Western philosophical terminology dominate proceedings, but it was also eagerly adopted by the Chinese, through Japanese translation, in the description of their own thought tradition. That part of the textual corpus that was traditionally assigned to the masters (zhuzi 諸子) along with some books of the Confucian Canon (jing 經)—continuing from the fifth century B.C. (by our count) up until the nineteenth century A.D.- - has been retrospectively branded as "Chinese philosophy" (Zhongguo zhexue 中國哲學). ${ }^{6}$

The strange thing is that this introduction of philosophy in China around the end of the nineteenth century, together with other disciplines and above all in the context of radical institutional changes, has practically marked the end of this very tradition of the masters. Those who nevertheless continue to study the old masters in a separate branch within philosophy departments no longer call themselves "masters," but rather "specialists" in Chinese philosophy. ${ }^{7}$ The curriculum of this separate branch consists mainly of traditional Chinese thought as it existed up until the introduction of Western thinking. Historical compilations of Chinese philosophy also often stop at the end of the nineteenth century or the beginning of the twentieth. ${ }^{8}$ Thus, at the moment when Chinese philosophy was retrospectively created or recognized, it also largely ceased to exist as a living tradition. "Chinese philosophy" seems to have died of its own birth: "Chinese philosophy" (of the traditional masters) and "philosophy in China" (at modern universities) exclude each other in the sense that, since the introduction of the latter, the former could only continue to exist in a foreign institutional setting, as a separated corpus and object of study. The fatal allergic reaction that the Chinese masters have developed toward this strange discipline raises questions regarding their combination: is this actually Chinese? And is it still philosophy?

This short analysis of the expression "Chinese philosophy" lends some plausibility to doubts concerning its legitimacy. But the dispute is not thereby settled. The next two steps of this essay shall construct a typology of the debate, following above all the lead of contemporary Chinese scholars who, not surprisingly, have more at stake in this question than we do.

\section{A Conflict over Facts}

At the bottom level of this debate one can distinguish two opposing positions, which imply, although sometimes also explicitly state, that Chinese philosophy either does or does not exist. One could call this first level a disagreement over facts, a level that is quickly overtaken once one is able to articulate and ground it in argument. But it is nevertheless worthwhile to explicate and reflect upon the characteristics of these two opposing positions. 


\section{First Position: Chinese Philosophy Does Not Exist}

The position that denies the legitimacy of Chinese philosophy is primarily, though not exclusively, implicit and Western. The strongest arguments are of both a historical and a theoretical nature. The historical argumentation departs from the irrefutable fact that philosophy is a well-defined discipline that came into existence in Greece and has expanded throughout the West, just as the masters (zhuzi) are considered a product of Chinese culture. The masters lived between the fifth and third centuries before our era in a region toward the lower reaches of the Yellow River, during a period of social mobility and relative affluence, and when there was a need for political advice. Just as the West cannot lay claim to its own "zhuzi," there were no "philosophers" at that time in the area that we now call China. It cannot be denied that philosophy has quickly spread itself over the whole world within just a century-as have so many other cultural products of the West-and that it has also set root in China. But the present existence of "philosophy in China" does not yet justify the retrospective appropriation of this term by a thought tradition that was ignorant of the then still exclusively Western discipline.

But this historical argument does not stand alone. Had the resemblance between the Chinese masters and the Western philosophers been convincing enough, then there would have been little opposition to their respective identification. We speak of Chinese houses and palaces without implying that these constructions exactly coincide with European architecture. For this reason, the historical line is often coupled with a theoretical argument that states that the Chinese masters do not in general-and certainly not entirely_-satisfy the conditions of philosophy. Western academics may, of course, differ regarding the definition of this term, but there is nevertheless a vague consensus that allows for a variety of writings under the label of philosophy, but not for just anything. Philosophy must give the appearance of systematicity, reflection, and rationality; it must differ from science and religion; and it must be divisible into various subdisciplines such as metaphysics, logic, and epistemology. A great deal of the teachings of the old Chinese masters from the so-called Golden Age of Chinese philosophy (the fifth to third centuries B.C.) rarely meet these demands. Thinkers like Laozi and Confucius, who are traditionally branded as the founders of Taoism and Confucianism, respectively, expressed themselves in short proverbs, aphorisms, or conversations without concerning themselves too much with systematicity, logic, or any other philosophical criterion.

Finally, this theoretical argument is lent further currency from the recent historical context within which China's masters were re-baptized as philosophers. This conversion was inspired not only by a grounded conviction in a striking resemblance, but rather by the solicitude of national strength and self-worth. China had undergone much foreign humiliation since the Opium War, and its internal situation had been cause for concern as well. The country wanted to rebuild itself on the Japanese model, for which China sought foreign inspiration. Seeing that philosophy in the West seemed to accompany strength and esteem, Chinese scholars decided not only to train themselves in Western philosophy but to label as such their own inherited thought tradition. The success of this argument in China can of course 
be reversed with equal vigor by Westerners: the conversion of masters into "Chinese philosophy" was predominantly a political issue, not the result of careful consideration. ${ }^{9}$

\section{Second Position: Chinese Philosophy Exists}

The second position is best and most explicitly represented in contemporary China. But it also exists, although more implicitly, in the West. The fact that the first position exists above all in the West does not mean that all Westerners are won over by it. Perhaps the anonymous majority assumes that something like Chinese philosophy must exist since many bookshops have dedicated a section to it, albeit between the sections on "astrology" and "erotic massage," and since various universities provide lectures on it, albeit not at philosophy departments. ${ }^{10}$ This vague consensus that something like Chinese philosophy must exist says nothing of people's knowledge or appreciation of it: even Hegel spoke of Chinese philosophy without attaching any positive significance to it. ${ }^{11}$

In comparison with the implicit power of the first position in the West, the second position leads a somewhat more explicit existence in contemporary China. The modern Western concept of philosophy that reached China at the end of the nineteenth century did not introduce itself as the proud ambassador of a particular culture-such as French wine or Belgian chocolate-but as something universal, a rational pursuit that every respectable culture must be able to discover within itself. This discovery progressed very smoothly: as European missionaries in the seventeenth century had already remarked, China had already known twenty-five centuries of philosophical tradition. According to this second position, the word "philosophy" is quite simply the Western term for the discussions and speculations of, by and large, the traditional "masters," despite the cultural variations. ${ }^{12}$

Because this position is more explicit, its representatives are also more clearly identifiable. The most famous of them was Feng Youlan 馮友蘭 (1895-1990), and the oldest was perhaps his mentor, Hu Shi 胡適 (1891-1962). The illustration of the second position is dominated to a great extent by their reasoning. Feng Youlan studied at Columbia University, taught at American and Chinese universities, and in later life was awarded with honorary doctorates in the United States and in India. Feng thought that Chinese and Western thinkers expounded on similar concerns and experiences and thus, without knowing it themselves, participated in the universal human project of philosophy. The foreword to the first volume of his A History of Chinese Philosophy does not explicitly argue that "Chinese philosophy" exists but reflects on its worth, thus assuming that it does exist. Through the questions he poses regarding the value of Chinese philosophy, one can make out that Feng's notion of philosophy is closely related to the above-mentioned vague Western consensus. His explicitly stated criteria are: systematicity, originality, and subdivisions. Furthermore, Feng holds that the masters didn't score too badly on these points, given the reader's willingness to engage them with some effort: there is an implicit presence of a structured philosophy in their texts, but it is up to us to make it explicit; philosophical progress and originality lie hidden in inconspicuous commentaries, and it 
is up to us to discover them; weak points in Chinese philosophy, in particular epistemology, metaphysics, or logic, are often the result of the masters' selective attention and conscious decision, and it is up to us to appreciate this. ${ }^{13}$

In his overview of the history of Chinese philosophy, Feng concerns himself primarily with the first point, namely the explication of implicitly regulated thoughts. For him, the best way to systematize ancient Chinese thought is through philosophy. His books are therefore teeming with all kinds of Chinese neologisms for terms such as "humanism" (renwen zhuyi 人文主义), “realism" (shizai zhuyi 实在主义), "pragmatism" (shiyong zhuyi 使用主义), "skepticism" (huaiyi zhuyi 怀疑主义), "utilitarianism" (gongli zhuyi 功利主义), “principles" (yuanze 原则), “essences" (benzhi 本质), “definitions" (dingyi 定义), "reason" or "truth" (daoli 道理), and so on. Feng thus offers his contemporaries new glasses with which to gaze upon their own tradition, providing an enrichment and liberation for which many Chinese intellectuals are still grateful.

The oldest philosophical presentation of Chinese thought in terms of philosophy, however, is to be found in the works of Hu Shi, in volume 1 of his Zhongguo zhexue dagang 中国哲学大纲 (Overview of Chinese philosophy), which appeared in 1919. As an enthusiastic proponent of John Dewey, pragmatism, and the American philosophy of that time, Hu Shi sought after traces of such pragmatic, logical, and realist thinking in the Chinese corpus. Within this project, his most renowned book, The Development of the Logical Method in Ancient China (1922), often goes radically beyond the centuries-old, traditional interpretations of the classical texts in order to bring to light unnoticed passages and thinkers. For example, the practical, utilitarian, and rather populist school of Mohism, which, under the pressure of Confucianism, historically never enjoyed much notoriety, was thrust to the foreground by $\mathrm{Hu}$ Shi. ${ }^{14}$

A philosophical reading of ancient Chinese thought is typical of the second position and can adopt different forms. An extreme variety of this is the compulsive use of the Marxist opposition between "idealism" (weixin zhuyi 唯心主义) and "materialism" (weiwu zhuyi 唯物主义). The communist vision, which classifies and interprets the masters according to this opposition, characterizes the idealists as aristocrats concerned with all sorts of abstract, metaphysical truths and repressive moral principles, while the materialists were prized for their resistance to this and their attention to concrete, material reality. A first tendency within these Marxist parameters consisted of defining all Chinese thinkers from before the liberation as "idealistic." Thereupon followed the tendency to interpret the whole evolution of Chinese thought in terms of a progressive dialectic between two streams of thought, and a gradual but constant growth toward materialism. ${ }^{15}$ From the 1950 s onward until the early 1980s, almost all disputes concerning Chinese philosophy in the People's Republic were carried out within this framework. Questions to be discussed inquired into which aspect of which classical philosopher and to what extent he was idealistic or materialistic, and how this echoed another aspect of his thought and social background. It was most difficult to put the frame of thought itself into question, seeing that the government had imposed it as an objective, scientific, 
proletarian, and socially responsible method for opposing the Western bourgeois approach of those like Hu Shi and Feng Youlan.

Nowadays, this Marxist framework is often left in silence by the wayside, but it is seldom the target of direct attack. Not only are scholars conscious of avoiding politically sensitive issues, but the framework itself is so conceptually weak that it is largely undeserving of much philosophical attention. Nevertheless, this Marxist framework certainly had its value in providing a fresh perspective after a long history of predominantly Confucian domination in China. Namely, the opposition between idealism and materialism focuses attention on the social background of diverse thinkers and the influence this has had on their insights. It is encouraging to see how the sensitivity to political context and social background, now released from its Marxist categories, continues to stimulate fruitful research by young scholars such as, for instance, Wang Bo (b. 1965), lecturer in philosophy at Peking University. ${ }^{16}$

\section{An Evaluation of the First Position}

There is much that could be said for both positions, and a defense of one is simultaneously an attack on the other. An advantage of the first position is that it aims to avoid a problem of the second position, namely the conceptual confusion of which the retrospective attribution of a philosophy to traditional China was a part. But this confusion is like a mountain of which only the peak presents a stumbling block for the first position. To shed light upon this "peak," we need to view the mountain in its various articulations.

At its foot we locate the philosophical neologisms, which, despite their complexity, can be organized into three groups. ${ }^{17}$ The least problematic of these, from the standpoint of the conceptual confusion, are the transliterations through which the Chinese characters offer a primarily phonetic representation of the English term (e.g., luoji 逻辑 for "logic"). Equally unproblematic is the second group consisting of translations constructed on the basis of relatively neutral terms (e.g., keguan 客观, literally "view of the guest," and zhuguan 主观, literally "view of the host," for the concepts "objective" and "subjective," respectively). The most problematic, however, because most confusing, is the third group of philosophical neologisms, which were formed from the translation of separate or integrated endemic terms that appeared to overlap with the corresponding Western ideas, but that also covered a rich and controversial gamut of political, historical, and intellectual connotations. For example, the prevailing Chinese word for "reason" or "truth," daoli, is constructed from two terms that themselves have a history spanning more than two millennia: dao 道 ("way," "method," "doctrine") and li 理 ("pattern," "principle") belong to the most difficult-to-interpret concepts in the study of the masters, even for contemporary Chinese scholars. ${ }^{18}$

These neologisms brought about a multiply confused discourse. First, Chinese intellectuals translated and interpreted Western philosophy via such neologisms, which on the one hand were foreign and Western, but on the other hand also familiar and ripe with traditional meaning. This shortcoming was unavoidable and is not part of the protests concerning the first position. A second phase of complexity, 
also no great obstacle for them, came about when researchers of Chinese thought began to interpret their own ancient texts through these neologisms instead of through the familiar and trusted endemic concepts. The fact that the Chinese masters have not always come out of this complex operation in the best light is a point of criticism of the second position that we shall expand upon in a moment. But what does present a problem for the first position - the mountain peak-is the retrospective usurpation of the title "philosophy" by the Chinese masters, the confrontation that is thereby made possible, and the strange chimeras that can and often do flow from this confused discourse. In this way, for example, Hegel's idea of Begriff is first translated or explained by the above-mentioned Chinese term li. This concept was important in the Neo-Confucianism of the twelfth century, in particular for the thinker Zhu Xi (1130-1200). As a result, one comes across mind-boggling studies such as the article "Short Comparative Analysis of the Theory of $L i$ in Zhu Xi and Hegel" - as if Hegel had ever participated in the Chinese debate concerning $l i$ and as if the philosopher Zhu Xi had preempted his Western counterpart by about seven centuries. ${ }^{19}$

An analysis of this conceptual confusion explains the resentment felt by those within the first position. But this position also implies a significant disadvantage: the critics of "Chinese philosophy" betray problematic presuppositions concerning the nature of understanding and communication. They seem to believe intercultural communication or even ordinary conversation to be successful only in those cases where information appears to traverse the gap between the head of the transmitter and the head of the receiver without distortion or hindrance. This, sketched simply, is the prevailing ideal of communication. But the more pertinent question is whether this situation is even possible, let alone desirable.

Bertrand Russell once claimed that fruitful communication consists precisely of the opposite, that it results from the discontinuity between the different contexts in which a concept comes to be articulated and from the new associations to which it may give rise there. ${ }^{20}$ If a partner in conversation were to repeat one's words entirely unchanged, like a mere echo, then one would very strongly suspect that neither understanding nor any form of communication had taken place. One experiences something as fruitful communication only when the response or explanation differs. The seeds of communication that we spread about seem to take root in a somewhat foreign soil. Difference is a sign of understanding, but it can also be a source of misunderstanding. Successful understanding is closely related to understanding differently, and thus also-and perhaps inevitably - to misunderstanding. Thus, understanding and misunderstanding present themselves not as clearly distinguished poles, but rather as rivals, nevertheless intimately bound to each other. It is becoming increasingly difficult, although no less important, to keep the two apart. The melting pot of misunderstandings resulting from the fact of China's self-molded philosophy has parallels in the Roman adoption of Greek concepts, the Chinese translation of Buddhist notions, and, indeed, on a smaller scale, in every form of interpretation or conversation. ${ }^{21}$

A vision of communication that attempts to overcome all difference begins with 
an equally erroneous expectation of transparency, as if Westerners could have perfect insight into the meaning of Western terms, and the Chinese into theirs. The meanings that words contain are not only multiple and changeable but also not crystal clear. The term "philosophy" is, in fact, a good example of this. In the seventeenth century, the missionaries did not find it difficult to brand Confucius' Analects or the Book of Changes as philosophy, since they maintained a far wider concept of philosophy than what tends to be the case today. Even the division of science as a separate domain of knowledge had not yet taken place. From this perspective, the question of whether ancient Chinese texts can be called "philosophy" is not so much a Chinese problem but the result of a severe contraction of the notion "philosophy" in the West. Promoters of the first position should as a consequence remove many ancient Greeks texts, together with the Chinese masters, from the general "Introduction to Philosophy" course. Modern interpretations often (and partly inevitably) do with Plato's writings what Feng Youlan did with the masters: select, systematize, and present them in contemporary terms.

\section{An Evaluation of the Second Position}

With Feng Youlan we are now in the midst of the second position. Feng believes that Chinese philosophy truly does exist and furthermore insists upon interpreting the masters with a predominantly Western philosophical jargon. An initial advantage of this approach is that a dialogue with Western colleagues was made possible: through Feng Youlan's books presenting Confucius" "humanism" and Mozi's "utilitarianism," the masters were given a recognizable place within a familiar discourse. Thus, for the first time, this rich and fascinating intellectual heritage was made accessible to a wide audience in the West, thanks not only to its philological but above all to its conceptual translation. A second advantage of this approach is that the Chinese public was given a new perspective on their own tradition. Even today, Chinese scholars experience this renewal as a release from a fossilized Confucian tradition, which after more than twenty centuries had exhausted its potential for debate and renewal and no longer appeared appropriate for the modern challenges confronting the country. Feng Youlan's orientation has allowed for communication and a renewed reflection, without losing the focus upon difference.

The disadvantages of this position have already been mentioned with the advantages of the first. But while the emphasis there was on the Western rejection of an unfair identification between the "masters" and the "philosophers," we can now focus on the disadvantages for the Chinese masters themselves. By forcing them into a philosophical jargon, traditional Chinese discussions and insights risk being cut into incoherent pieces: one throws together what does not belong together, and misses connections that are crucial within the Chinese context. Westerners who search for maxims and universal principles in ancient Chinese texts are like Chinese masters who would sift through the whole corpus of Western texts-from political manifestos to philosophical treatises-in search of prescriptions for coffins, without taking into account our current intellectual categories or philosophical interests. Due to ritual stipulations, the thickness of coffins was a controversial topic for the Chinese 
masters but has not been coherently dealt with in the West, except perhaps in the trade literature of funeral directors. A pernicious result of such intellectual mutilation is that the Chinese insights are exposed as primitive or naive forms of familiar Western concepts, insights, and discussions that are themselves never called into question.

In the People's Republic, such a critique is almost unheard of. Despite the few critical voices that have come and gone, the philosophical jargon has remained to a large degree unscathed. ${ }^{22}$ The dominant study of the masters-after the Marxist intermezzo and since the Open Door politics of Deng Xiaoping (1979)—is again beginning to reveal a resemblance to Feng Youlan's approach from before the 1960s. But through increasing contact with Western colleagues and no doubt as a result of independent evolutions and growing nationalism, more and more Chinese scholars are beginning to question the influence of Western philosophical jargon, originally and above all in Taiwan and Singapore, but also increasingly in the People's Republic. ${ }^{23}$

\section{A Conflict over Concepts}

With this evaluation, we have arrived at a point where the discussion over facts leads into subtler argumentation concerning the concept of "philosophy" itself. Feng Youlan's work and the reaction to it from both China scholars and Chinese scholars reveals how explication and argumentation at the level of facts leads to a discussion of concepts. ${ }^{24}$ I will appeal to the distinction made in analytical philosophy between the "descriptive" and "emotive" meaning of terms, to divide discussions concerning the notion "philosophy" into two major types: on the one hand those that instigate a renewed definition of the content of this notion (its descriptive, conceptual meaning) and on the other those that dispute its current appreciation (the emotive meaning). As an illustration of these different argumentative strategies, one could consider two opposite approaches to the notion of "etiquette" as different ways to defend one's preference to eat with bare hands at a banquet. One strategy would be to state that this behavior constitutes "true etiquette," departing from the common content of this notion, but preserving its currently positive appreciation; the alternative would be to attack the prevalent value of etiquette in general, without challenging its prevalent meaning (eating with a knife and fork) in our society. ${ }^{25}$ Viewed from this perspective, the opposition between the two initial positions in the debate on "Chinese philosophy" is based on a remarkably common implicit ground, where neither the positive appreciation nor the current interpretation of the notion "philosophy" are being questioned.

One would imagine that the sharpest possible contrast with this common ground would be a position that undermines both of these presuppositions by questioning the prevalent understanding of philosophy as well as its value. But this position, understandably, has few supporters: one who feels nothing for philosophy is unlikely to take the effort to lend it new content. For the two most important alternatives to come to light in the next steps, attention to one of the two kinds of meaning is 
generally, but not necessarily, emphasized at the expense of the other. It is far from surprising that a positive appreciation of philosophy will demand a new and broader interpretation of the term, allowing the ancient Chinese masters to take part in it. Similarly, it is normal that a break with the current appreciation of philosophy does not invite a new content of the term.

Thus, we shall discuss as a third position the view that presupposes the value of philosophy while explicitly questioning its prevalent content. This view is often related to the second position - the assertion that Chinese philosophy existsproviding it with a more explicit defense and argumentative force. As a fourth position we shall discuss the view that does not question the prevailing interpretation of the term, but rather the value of the philosophical project: why should China even have had a philosophy? This position accompanies the first, but is more elaborate and predominantly Chinese in its representation and concern.

\section{Third Position: What Is the Meaning of "Philosophy"?}

The third position is held above all by sinologists with philosophical training and, analogously, by philosophers with sinological training. They claim, on the one hand, that the tradition of the Chinese masters sufficiently resembles the wider Western philosophical tradition - and not simply its modern variant-to be labeled as philosophy. After all, the masters pose questions of deep human concern while substantiating their ideas with examples and arguments. On the other hand, their themes and forms of reasoning are sometimes so fundamentally different from those of their Western counterparts that the Chinese masters offer a unique opportunity to question, in a philosophical manner, the current notion of "philosophy" itself.

Indeed, this may be something that Western philosophers tirelessly continue to do: strive for the ideal of objectivity or open-mindedness. Within the humanities this ideal can best be realized in confrontation with what is most different; and what is more different from our Western philosophical tradition than ancient Chinese thought? The third position admits that the adjective "Chinese" does have an influence on the term "philosophy," but a beneficial one, because it breaks through the unarticulated-and therefore even stronger-modern limitations of the notion "philosophy" and its dominant categories.

Those who support the broadening of the prevailing term "philosophy" to encompass the Chinese masters perceive in Chinese thought not only the advantage of an entirely new perspective, but even a valuable alternative for what many consider to be an inveterate metaphysical tradition with its sharp contrast between reality and language, prescription and description, saying and doing, objective and subjective, self and other, and so on. It is no coincidence that the push for this appreciation of the Chinese heritage has arisen at the hands of critics of the Western tradition. According to them, we must focus our attention not on those ancient Chinese ideas that, after some adaptation, can be taken up within the circles of Western discussion, but precisely on those ideas that seem stubbornly subversive toward concepts and categories from the West.

A good example of this position is Herbert Fingarette, who, inspired by John 
Austin's vision of performative language use, rediscovered the value of the ritual word in the Analects of Confucius. In his small but influential book Confucius: The Secular as Sacred, he also reacts against the familiar subjective, psychologizing interpretation in terms of internal intention versus external deeds. The reversal, which Fingarette describes in his Preface, is typical for this third group:

When I began to read Confucius, I found him to be a prosaic and parochial moralizer; his collected sayings, the Analects, seemed to me an archaic irrelevance. Later, with increasing force, I found him a thinker, with profound insights and with an imaginative vision of man equal in its grandeur to any I know. Increasingly, I have become convinced that Confucius can be a teacher to us today - a major teacher, not one who merely gives us a slightly exotic perspective on ideas already current. He tells us things not being said elsewhere-things needing to be said. He has a new lesson to teach. ${ }^{26}$

Thus Fingarette reacts against the traditional interpretation of Confucius that is characteristic for the second group and that, according to him, represents the master as an uninteresting variation of dusty old Western ideas.

\section{Fourth Position: What Is the Value of "Philosophy"?}

Philosophy is not universal, nor is it a trait of rationality, but is a typically Western discourse, with its strengths (such as the ideals of neutrality and universality) as well as its weaknesses (e.g., its limited and purely academic scope). ${ }^{27}$ Just as shadowboxing (taijiquan) is having success in the West, philosophy is spreading with much prolificacy through China, but this takes nothing away from either of their original cultural bounds. With this idea, a minority of mainly Chinese intellectuals constitutes a fourth and final major position.

Philosophy is, and remains, a primarily Western cultural product, a strange and useless conversation in which European tribes have trained themselves, full of earnestness and sedulity. It is a very specific discourse that for some reason or other has maintained a high level of subscription in the mysterious West. I have yet to find this possible variation of the fourth position in Chinese sources, but it challenges in a powerful way the implicit valuation enjoyed by philosophy in the previous positions. The fourth position is closely connected to the first, which is proclaimed by mainly Western proponents, but it replaces the implicit appreciation for philosophy by one or more explicit emotive meanings, such as contempt, pity, indifference, wonder, or admiration.

One variant of this position explicitly admires philosophy and denounces the bankruptcy of the Chinese tradition. Intellectuals attack China for its lack of philosophy and other Western values; the May Fourth Movement of 1919 and the "culture craze" (wenhua 文化热) of the 1980s were moments in which this vision was relatively strong. But not all voices in this group resound with a sharpness equal to that of Liu Xiaobo (b. 1955), who prefers Western philosophy for its intellectual fascination and because of its superiority, according to him, over traditional Chinese thought. He even goes so far as to claim that Western philosophy is necessary to haul China out of its backwardness. The only thing that can save China, so he has said in a controversial interview, "is three hundred years of foreign colonization." 28 
A milder variant of the fourth position has become more current since the "national tradition craze" (guoxue 国学热) of the 1990s. Nowadays one seldom hears it said that philosophy is Western without the qualification that the Chinese tradition can boast a worthy alternative in a corpus of masters. This variant characterizes Western philosophy as closely linked with, although also rivaling, religion and science, while the Chinese masters are said to offer a compass for navigating through one's personal, family, social, and political life. A certain congeniality with their own tradition often lies hidden beneath such comparisons. Here one shares with the third group an interest in traditional Chinese thought without, however, redefining the descriptive meaning of the term philosophy. Here also one can see the desire to protect the masters' corpus from philosophical mutilation. ${ }^{29}$

An extreme version of this variation would have it that Westerners and Chinese simply cannot understand each other's thought because they differ so fundamentally. Liu Dong, a researcher at the Academy of Social Sciences, even claims that non-Chinese are entirely unable to grasp either past, present, or future Chinese thought. Sinologists or China scholars also lack the right feel for the Chinese context. They do not understand the "consciousness" with which China deals with its complex situation, and they allow themselves to be led astray by their own interests and new trends. Even Chinese scholars working abroad misinterpret Chinese thought, according to Liu, as they view China through Western philosophically colored glasses. ${ }^{30}$ Even though a famous Chinese proverb claims that "standing on mount Lu one cannot see the true face of the mountain," and that distance can thus be intellectually advantageous, Liu Dong articulates a much-held view among Chinese scholars. ${ }^{31}$

To conclude, there are two prevailing Western varieties of this fourth position: one is the explicit response of Western philosophy professors challenged to ground their implicit position. It is then that they gladly accept the compromise that grants China, as a consolation prize, the patent on a sort of practical wisdom or pragmatic sensibility. As a consequence they need not adapt either the content or the title of their "Introduction to Philosophy." And finally, the sinological variant considers many Chinese texts philosophically interesting because they question trusted categories, but it does not therefore consider the teachings of the ancient master to be "philosophy." The resemblance to the Western philosophical tradition is, of course, quite real-otherwise there would be no confrontation. But the identification of both traditions has brought with it so much confusion that they find it too problematic.

\section{Evaluation of the Conceptual Discussions}

Due to the fact that both these varieties are an elaboration of the first two positions, they are deserving of more or less the same evaluation. Thus we shall limit ourselves here to the respective conceptual components of their arguments. Here again the evaluation has already been implicitly posed by the argumentation of the opposing position.

The third position deserves appreciation for its critical orientation toward the currently limited notion of philosophy. The Chinese masters can indeed be 
philosophically more interesting in their resistance to prevalent philosophical categories than in their awkward incorporation within them. The absence in Confucius of an "internal" realm harboring thoughts and emotions is not necessarily a weakness of his thought, nor is the panoply of contradictory stipulations in the Analects necessarily a failure in clear thinking. China's foremost master does not always need correction at the hands of modern philosophers, and he also challenges our dominant metaphors (locating emotions inside) and academic habits (demanding strict definitions). Such a defense of the Chinese masters has a further implication, namely that it also reacts against an all-too-modern interpretation of premodern Western thinkers.

But the arguments of the third position have their weaknesses: as critique, they alert us to the influence of subconscious presuppositions, but their positive alternative is less convincing. With the bursting of the borders of the modern concept of philosophy, all Chinese masters are suddenly granted asylum in the field. Thus, an unchecked conceptual expansion allows room not only for the aphorisms of Laozi and the sayings of Confucius, but also, by analogy, for Biblical orations and parables. An all-too-generous expansion of the term "philosophy" leads to a concept that encompasses almost everything — and that, therefore, means almost nothing.

Where the third position mainly concerns itself with questioning the content of the term "philosophy," the contribution of the fourth position is its explicit attention to its emotive meaning. The Chinese masters need not undergo a philosophical "face-lift" in order to be interesting; indeed, they need not even be considered instantiations of philosophy. But here again lies the weakness of this position: in the danger that one assumes the ability to complete this critical attitude with a positive alternative. The more self-assured the alternative, the greater this danger is. The conviction that only China has unproblematic access to its own tradition is a kind of nationalistic counterpart of the universalism defended by the second position. Just as the notion "philosophy" to some extent remains inaccessible for contemporary Westerners, ancient Chinese ideas remain foreign to contemporary Chinese scholars. Not only is it impossible to turn back the clock and to purge China of all Western influence (the philosophical jargon included), but the ideal of transparent communication and perfect self-knowledge are also myths that are susceptible to the remarks made in the evaluation of the first position. It is not because we do not entirely understand the Chinese-and do not understand them in their own termsthat we therefore do not understand them at all. To "entirely understand" is the unattainable ideal of a problematic vision of understanding and communication.

\section{A Conflict of Sensitivities}

We have now exposed the first building blocks of a largely unarticulated debate. The four positions presented are not meant as descriptions of actual visions, but rather as types of argumentation and illustrations thereof. The sketchy presentation of each separate position has sometimes made explicit what many have never stated, while it has silenced arguments that sometimes do arise in concrete discussions. In order to 
represent in a precise and orderly fashion as many actual points of view as possible on the basis of these foundations, one would have to expand further upon a wide range of variations and combinations.

With this abundance of various visions concerning the legitimacy of Chinese philosophy, the reader perhaps wonders why this problematic has been branded an "implicit debate." The arguments that have been presented do indeed belong to a minority, and the elaboration of the last two positions in particular is relatively recent. But the fact that only a minority concern themselves with a question does not make the debate "implicit," as if one expected the whole world to be concerned with every problem. The debate is implicit in the sense that dominant and opposing opinions implicitly prevail with a certainty that is hardly ever questioned and that apparently requires no rational foundation. The four positions and their variations offer arguments that could support these various certainties but that have not led to consensus, nor have they been capable of significantly changing the reality of the situation. Fixation upon this argumentation and an endless progression of it has a pernicious consequence, namely that attention is being diverted from something entirely different: the sensitivity surrounding the entire problematic and the ineffectiveness of the respective arguments to break through it.

Both the sensitivity and the indecision characteristic of this discussion have to do with the fact that the concept "philosophy" is opaque for us, too. Every philosopher has his or her own vision and doubts about philosophy, which are usually discussed or temporarily settled during the first hours of class. The prevailing doubt and lack of consensus, however, do not discourage our institutions from continuing to function with an implicit, opaque, yet highly resistant notion of philosophy. This notion determines that the Bible, Proust, and Kundera generally do not form part of the curriculum, nor do non-Western thinkers, particularly if they are from the ancient past. But the literary extravagances of Nietzsche and the loose reflections of the late Wittgenstein are generally taught as philosophy, despite their striking resemblance, respectively, to the provocative fantasies of Zhuangzi and the sporadic utterances of Confucius.

It seems that the philosophers of our curriculum do not share one, albeit for the time being disputed, essence with one another, but rather various and particular characteristics, such as the multiple, overlapping resemblances of family members. Thus seen, philosophy appears to be a concrete, culturally bound, diverse, and dispersed whole of conversations constantly referring to each other. Founded in Greek soil, it has now grown over twenty-five centuries within a specific culture, language group, and ethos. Even though ever-larger parts of the world are now taking part in this conversation, it remains a Western cultural product that influences its new interlocutors while being influenced by them.

The appeal to Wittgenstein's idea of family resemblances ${ }^{32}$ is not intended only to follow his lead in deserting the search for a common essence dwelling behind its manifestations or to minimize the relevance of the discussions sketched out above and thus settle the dispute in favor of the first position. The analogy with family resemblances can be further developed in a positive way, setting the debate on a 
new track. The members of a family may not all share a common essence, but there is something else that binds them: a family name. In contrast to a concept, whose meaning (be it either emotive or descriptive) may form the object of debate, the family name is something arbitrary and empty of meaning (except perhaps for the concrete reference to other family members or bearers of the same name). A family name has no abstract essence and cannot be defined. The sensitivity of discussions concerning philosophy lies also, as I will argue, in the fact that this term to some extent functions like a family name.

The history of philosophy in the West can then be read as the chronicle of a large family. Descendants of the clan are usually born through studying, lecturing, and publishing in philosophy. Now and then a bastard is spawned-from literature, linguistics, history, or anthropology - whose right to the family name is unclear or disputed. Adoption can incite protest, particularly when a whole group of foreign masters come knocking at the door-a reaction that characterizes the first position. An outsider cannot just adopt our name without justification, even though we don't quite know why we ourselves are deserving of that name. The protest cannot be adequately founded because there are no intrinsic reasons to let anyone in or keep them out. But the absence of a clear criterion of what philosophy is only makes the question that much more sensitive. The emptiness of the family name maintains the insecurity concerning the question of not only who has rights to it but also the responsibilities it imposes. One must hold the name high, but what are its demands? Confirmation comes from the onlookers (who knew our forefathers and the ideals for which they stood), whose scrutinizing gaze accompanies us.

Our Chinese colleagues find themselves in a similar though even more sensitive predicament: their academic activity also derives meaning from the framework within which they operate (the philosophy department), while they are aware that one of their forefathers was an adopted child. They know that even after a century, Western philosophers often do not consider them family members of equal standing. For this reason, some of them reject the adoption and wish to continue without the name and demands of "philosophy," an option taken on board by the fourth group. The majority of Chinese, however-constituting the second and third positionspropose that the masters do belong to the great philosophical family. But only the supporters of the third position feel themselves called upon and empowered to compel the family to adapt itself to its adopted children.

This analogy is far from perfect since the term "philosophy" is not as empty and sensitive as a family name is: one can choose for philosophy, one can be good at it, and there are, after all, criteria circulating for inclusion and exclusion, as the supporters of the different positions have demonstrated. But that does not detract from the fact that the Western relation to philosophy also bears something of the duplicitous position within which the family name places us: we are attached to something that remains inaccessible to us; we are rooted in our own "uprootedness." 33 Insofar as the disagreement over the existence of Chinese philosophy displays analogies with such a family dispute, reflection over name giving and adoption ought to be part of our reflection. Of course, the further expandable arguments aimed at giving 
the various positions a foundation remain relevant, but along with them one must maintain some focus on the vulnerability that hides behind the self-assuredness of these arguments.

We are deeply attached to philosophy; we are proud of it and indebted to it, but all this without conclusive argument. The adopted child also finds itself in this divided situation but it plays with more options for escape. The real question, however, is whether there are alternatives that can offer our Chinese colleagues a perfectly hospitable home. The fourth option, namely to leave philosophy altogether and settle down within one's own thought tradition-and in the extreme case to exclude all foreigners - strives for a sense of homeliness and security of which some Westerners in the first position also dream. Not only are both groups overtaken by the historical clock (the institutional existence of "Chinese philosophy" in China cannot be undone), but they also leave no room for the un-homeliness that exists in every family, not only for adopted children but for every descendant. To focus one's attention exclusively on the rational arguments in the question of the existence of Chinese philosophy and to maintain an inflexible attitude within the ensuing debate represent attempts to settle definitively the vulnerability of our existence-attempts ultimately destined for failure.

Notes

This is a reworked translation of a paper originally written in Dutch, "Bestaat er zoiets als Chinese filosofie? Argumenten van een onuitgesproken debat," in Krachten voor de toekomst: Lessen voor de eenentwintigste eeuw (Leuven: Davidsfonds, 2000), pp. 309-331. I want to express my gratitude to Jeremy McKenna for helping me with this translation.

1 - There are more than thirty philosophy departments at Chinese universities, four with important centers for Chinese philosophy: Peking University, Nanjing University, Wuhan University, and Fudan University. There are also research centers and research units for Chinese philosophy in the national and local Academies of Social Science.

2 - For "Chinese religion," see Joël Thoraval, "Pourquoi les 'religions chinoises' ne peuvent-elles apparaitre dans les statistiques occidentales?" Perspectives Chinoises 1 (March 1992): 37-44. For "Chinese science," see Nathan Sivin, "Why the Scientific Revolution Did not Take Place in China-Or Didn't It?" Explorations in the History of Science and Technology in China, ed. Li Guohao, Zhang Mengwen, and Cao Tianqin (Shanghai: Chinese Classics Publishing House, 1982), pp. 89-106.

3 - Because in modern Chinese these three entities fall under the expression Zhongguo zhexue, their mutual relation is also far from univocal, even for contemporary Chinese scholars. See, for example, Feng Youlan, Zhongguo zhexueshi xinbian 中国哲学史新编 (A new edition of the History of Chinese 
Philosophy), vol. 7 (Taibei: Landeng, 1991), pp. 162-163; Feng makes an explicit distinction between "philosophy in China" and "Chinese philosophy," but not between its traditional and present-day varieties.

4 - See Zhong Shaohua 鐘少華 “Qingmo Zhongguoren duiyu 'zhexue' de zhuiqiu” 清末中國人對 “哲學”的追求 (Late Qing Chinese pursuit of "philosophy"), in Zhongguo wenzhe yanjiu tongxun 中國文哲研究通訊 (Taibei: Academia Sinica) 2 (2) (1992): 159-189. For a brief reconstruction, see Joël Thoroval, "De la philosophie en Chine à la 'Chine' dans la philosophie: Existe-t-il une philosophie chinoise?" Esprit, no. 201 (May 1994): 9. This article was my major source of inspiration for the four positions of the typology explained below.

5 - See Nicolas Standaert, "The Classification of Sciences and the Jesuit Mission in Late Ming China," in Jan de Meyer and Peter Engelfriet, eds., The Jesuits: Cultures, Sciences, and the Arts, 1540-1773 (Leiden: Brill, 2000), pp. 287-317.

6 - The oldest Western title referring to a Chinese master as philosopher is Couplet's Confucius Sinarum Philosophus of 1687. Earlier titles refer to "Sapientia Sinica" and "Sinarum scientia politico-moralis." For an overview of early Western sources on Chinese philosophy, see Iso Kern, "Die Vermittlung chinesischer Philosophie in Europa," in Friedrich Ueberweg, ed., Grundriss der Geschichte der Philosophie: Die philosophie des 17. Jahrhunderts, Band 1, "Algemeine Themen Iberische Halbinsel Italien," ed. Jean-Pierre Schobinger (Basel: Schwabe \& Co Ag. Verlag, 1998), pp. 225-295.

7 - Or Zhongguo zhexuejia 中国哲学家, which is as ambiguous as the abovementioned expression Zhongguo zhexue.

8 - The only Dutch overview of Chinese philosophy, by Karel van der Leeuw, voices the consensus when the author claims that "In the early part of this century, [China's] autonomous philosophical tradition abruptly ceased to exist. Because this is not a history of philosophy in China, but of Chinese philosophy, my story ends here." See his Het Chinese denken: Geschiedenis van de Chinese filosofie in hoofdlijnen (Amsterdam: Boom, 1994), p. 338.

9 - Concerning this transition period in Chinese thought, see also Anne Cheng, "Epilogue," Histoire de la pensée chinoise (Paris: Seuil, 1997), pp. 605-610. For her conscious choice of "pensée chinoise" and not "philosophie chinoise," see 29-31.

10 - "Chinese Philosophy" or "Chinese Thought" is generally taught at departments of sinology, Asian languages and culture, or religion, and very exceptionally in philosophy departments or in interdisciplinary courses. The University of Hawai' $i$ is an exception, with compulsory graduate courses on Chinese, Indian, and comparative philosophy.

11 - Hegel (1770-1813) found Chinese philosophy to be naive, primitive, and philosophically uninteresting manifestations of an early stage in the evolution 
of Geist. See Hegel's Lectures on The History of Philosophy, trans. E. S. Haldane and F. Simson, 3 vols. (London: Routledge and Kegan Paul, 1968), vol. 1, pp. 119-125.

12 - It is inevitable that the words with which we describe ancient China cover different entities. This is in fact what nouns do even within a single culture: they stand for a plurality of different things.

13 - See Fung Yu-lan, A History of Chinese Philosophy, trans. Derk Bodde, 2 vols. (Princeton: Princeton University Press, 1937, 1973), pp. 1-6. This introduction is a reworked and condensed translation of Feng Youlan, Zhongguo zhexue shi (Shanghai: Shenzhou Press, 1931), pp. 1-27.

14 - For an overview and short discussion of the first Chinese works on "Chinese philosophy" see Ge Zhaoguang 葛兆光, Qi shiji qian Zhongguo de zhishi, sixiang, yu xinyang shijie 七世纪前中国的知识, 思想与信仰世界 (The world of knowledge, thought, and belief in China before the seventh century), Zhongguo sixiang shi, di yijuan 中國思想史，第一卷 (History of Chinese thought, pt. 1) (Shanghai: Fudan University, 1998), pp. 4-5.

15 - Pleas for a more subtle use of "materialism versus idealism" were voiced at two major conferences on Chinese philosophy held in 1957. See China News Analysis, no. 219 (March 1958).

16 - See, for example, his "Laozi 'ziran' guannian de chubu yanjiu" 老子“自然” 观念的初步研究 (A first investigation into Laozi's concept of “evidently so"), in Zhongguo zhexue shi 中国哲学史 3 (4) (1995): 51-55.

17 - For the complexity and variety of the borrowed words, see Lydia H. Liu, Translingual Practice: Literature, National Culture, and Translated Modernity: China 1900-1937 (Stanford: Stanford University Press, 1995), and Chen Liwei, "Zaoqi de Ying Hua zidian yu Riben de yangxue" (Early Chinese-English dictionaries and the Japanese study of the West), Yuanxue 1 (1994): 277-294.

18 - See Chen Lai, "The Concepts of Dao and Li in Song-Ming New-Confucian Philosophy," in Contemporary Chinese Philosophers on Chinese Philosophy, special issue of Contemporary Chinese Thought 30 (4) (Summer 1999): 924.

19 - See Michael Lackner, "Les avatars de quelques termes philosophiques occidentaux dans la langue chinoise," Etudes chinoises 12 (2) (1993): 145-146.

20 - See Bertrand Russell, "The Philosophy of Logical Atomism," in Logic and Knowledge, ed. Robert Monsh (London: Allen and Unwin, 1956, 1984), pp. 195-196.

21 - Martin Heidegger perceives the transition of Greek concepts into the Roman world in highly negative terms. See his Parmenides, G. A. 54 (Frankfurt am Main: Klostermann, 1982), p. xv. Kenneth Chen's account of the Chinese adoption of Buddhist terms is of a more historical character. See his Buddhism 
in China: A Historical Survey (Princeton: Princeton University Press, 1964, 1973), pp. 68-69.

22 - Examples of this are innumerable. See, for example, Chen Guying's foreword to the first volume of Daojia wenhua yanjiu 道家文化研究 (Investigation of the Taoist culture) (1992), pp. 2-3. Criticism of this position is expressed in the fourth position.

23 - See, for example, Wang Bo, "What Did the Ancient Chinese Philosophers Discuss?" in Contemporary Chinese Philosophers on Chinese Philosophy, special issue of Contemporary Chinese Thought 30 (4) (Summer 1999): 2840.

24 - In this article, I use "sinologist" and "China scholar" interchangeably and in a broad sense referring to (often non-Chinese) scholars studying China, past and present, in institutions (mostly) outside China.

25 - This distinction was suggested $\mathrm{I} \rightarrow$ Charles Stevenson in "Ethical Judgments and Avoidability: Persuasive Definitions," Mind 47 (1938): 331-350, where he deals with "conceptual" and "emotive" meaning. In his book Ethics and Language (New Haven: Yale University Press, 1944, 1972), "conceptual" is replaced by "descriptive."

26 - See Herbert Fingarette, Confucius: The Secular as Sacred (New York: Harper and Row, 1972), p. vii; my emphasis.

27 - See Wang Bo 王博, Laozi sixiang de shiguan tese 老子思想的史官特色 (The characteristics of the public servant in Laozi's thought) (Taibei: Wen Jin Press, 1993), pp. 171-188.

28 - See Jin Zhong, "Wentan 'hei ma' Liu Xiaobo fanwenji" (An interview with the "black horse" of the literary world, Liu Xiaobo), Jiefang yuebao, no. 12; quoted in Woei Lien Chong, "Kant and Marx in Post-Mao China: The Intellectual Path of Li Zehou" (Ph.D. diss., Leiden University, 1999), pp. 241-242.

29 - Ge Zhaoguang gives an overview of the arguments and proponents of this position in Qi shiji qian Zhongguo de zhishi, pp. 5-8. Famous supporters of these positions have been Liang Qichao, Jin Yuelin, Fu Sinian, Tang Junyi, and Chen Qiyun.

30 - Liu Dong, "Qinggao renwei de 'yangjingbinxuefeng'" (Watch out for purposeful "pidgin scholarship"), Ershiyi shiji 32 (1995): 4-13. This article, along with several of the reactions it provoked, are discussed in "Intellectuals: The Self and Others," in China News Analysis, no. 1556 (March 1996).

31 - This view has partly to do with the fact that the Chinese masters, unlike their philosophical counterparts, are not so much linked to the sciences and their pretensions of universality, but rather to art and its more particular tendencies.

32 - Ludwig Wittgenstein employs the term "game" as an example of how it is impossible to explicate the essence that all games share, although one can point 
to elements that are characteristic of different games, so that they belong together like a group of family members. See his Philosophical Investigations, trans. G.E.M. Anscombe (Oxford: Basil Blackwell, 1958, 1984), §66-§67.

33 - This metaphor and the development of this idea are indebted to the thought of Rudi Visker. See his Truth and Singularity: Taking Foucault into Phenomenology (Dordrecht: Kluwer, 1999), pp. 11-13. 